\title{
AVALIAÇÃO ESPAÇO-TEMPORAL DA PRECIPITAÇÃO DA MICRORREGIÃO DO BREJO PARAIBANO
}

\author{
CHAGAS NETO, Pedro - pcneto.rt@gmail.com \\ Universidade Federal da Paraíba/UFPB
}

\author{
ARAÚJO, Lincoln Eloi de - lincolneloi@yahoo.com.br \\ Universidade Federal da Paraíba/UFPB
}

\begin{abstract}
RESUMO: A precipitação no Nordeste brasileiro apresenta uma grande variabilidade, devido aos diferentes sistemas produtores de chuvas atuantes na região e ao fato de está localizado na região semiárida do Brasil. Com base nesta característica utilizou-se uma série histórica de precipitação de oito municípios, com 21 anos de dados cada a fim de verificar os ciclos secos e chuvosos, através do Índice de Anomalia de Chuva (IAC) e avaliar a variabilidade espaço-temporal da precipitação na microrregião do Brejo Paraibano. Desta forma, em relação a variabilidade temporal da precipitação, observou-se que dentro de cada ano existem dois períodos distintos, um período úmido que vai de fevereiro a agosto e um período seco, que vai de setembro a janeiro. $\mathrm{Na}$ variabilidade espacial da precipitação observa-se uma melhor distribuição da precipitação na região Oeste/Noroeste da microrregião, sendo mais evidente no mês de junho. Em relação ao IAC a microrregião apresenta boa variabilidade entre anos considerados secos e anos considerados úmidos, possibilitando assim uma melhor um equilíbrio nas fontes de reserva hídrica da área. Por fim, pode-se afirmar que a microrregião do Brejo Paraibano possui grande variabilidade na precipitação, sendo o período de fevereiro a agosto a melhor época para o plantio e aporte hídrico da região.
\end{abstract}

Palavras- chaves: Índice de Anomalia de Chuva, período úmido, período seco.

SPACE-TIME EVALUATION OF THE MICRO-REGION BREJO PARAIBA OF RAINFALL

ABSTRACT: Precipitation in the Brazilian Northeast presents a great variability, due to the different rain producing systems in the region and to the fact that it is located in the semi-arid region of Brazil. Based on this characteristic, a historical series of precipitation of eight municipalities was used, with 21 years of data each, in order to verify the dry and rainy cycles, through Rainfall Anomaly Index (RAI) and to evaluate the spatio-temporal variability of precipitation in the microregion of the Brejo Paraibano. Thus, in relation to the temporal variability of precipitation, it was observed that within each year there are two distinct periods, a wet period from February to August and a dry period, which runs from September to January. In the spatial variability of precipitation, a better distribution of precipitation is observed in the West / Northwest region of the microregion, being more evident in the month of June. In relation to IAC, the micro-region presents good variability between years considered dry and years considered humid, thus allowing a better balance in the sources of water reserve in the area. Finally, it can be stated that the Brejo Paraibano micro-region has great variability in rainfall, with the period from February to August being the best time for planting and water supply in the region.

Keywords: Rainfall Anomaly Index, wet season, dry season.

\section{INTRODUÇÃO}

$\mathrm{Na}$ região Equatorial, a variação tempo-espaço das variáveis meteorológicas, em especial a precipitação, está relacionada à atuação de fenômenos meteorológicos de diferentes escalas de tempo, que modulados por mecanismos oceano-atmosfera de escala interanual, sazonal e intrassazonal determinam a quantidade pluviométrica de determinadas regiões equatoriais (MOURA \& VITORINO, 2012). 
Segundo Araújo et al., (2008) os principais sistemas atuantes no Nordeste encontram-se os sistemas frontais (KOUSKY, 1979), a zona de convergência intertropical (UVO, 1989), os vórtices ciclônicos de ar superior (KOUSKY e GAN, 1981) e os distúrbios de leste (ESPINOZA, 1996). Vale destacar os Distúrbios de Leste que atuam desde o norte do Rio Grande do Norte até a Bahia, no período de maio a agosto; também a Zona de Convergência Intertropical que é considerado o principal sistema produtor de chuva no norte do NEB, atuando de fevereiro a maio, principalmente no estado do Ceará, oeste do Rio Grande do Norte e interior da Paraíba e Pernambuco (ARAUJO et al., 2008).

Na região semi-árida o crescimento de atividades antrópicas está associado com mudanças no regime de chuvas o que torna essencial o conhecimento de padrões atmosféricos a nível local (SANTOS et al., 2011).

Segundo Pereira \& Curi (2012) o estado da Paraíba, localizado na região Nordeste do Brasil, sofre com a escassez de recursos hídricos, decorrente, principalmente das suas características físico-climáticas, visto que praticamente $90 \%$ do território encontra-se inserido na região semiárida, caracterizada por apresentar irregularidade nas chuvas. O déficit hídrico do estado da Paraíba acentua-se no sentido do litoral ao sertão, região que se é percebida os mais baixos volumes nos reservatórios, típico de áreas semiáridas, com chuvas concentradas em determinados períodos do ano (PEREIRA \& CURI, 2012).

A precipitação é uma das variáveis climáticas mais importantes. O conhecimento desta é fundamental, não só para caracterizar o clima do continente, mas também para o planejamento de inúmeras atividades produtivas, tais como agricultura, pecuária, geração de energia hidrelétrica etc. A variação de longo prazo desta variável afeta diversas atividades econômicas (FREITAS et al., 2010). A precipitação pluvial é a única fonte de suprimento de água no semiárido nordestino, que ao escoar superficialmente é barrada em açudes, sendo usada para abastecimento público ou privado ou captada e armazenada em cisternas, para fins potáveis (PEREIRA \& CURI, 2012).

Com base nesta precipitação irregular faz-se necessário o monitoramento através do emprego de índices climáticos. Com base neles, pode se desenvolver um sistema de acompanhamento das características dos períodos de seca ou úmidos, com informações anuais, sazonais ou mensais, com as quais pode-se conhecer profundamente a climatologia de uma região, e verificar os impactos que o clima global causa sobre a distribuição pluviométrica local, ou seja, a regionalização da precipitação para determinado local (ARAUJO et al., 2009).

Segundo Santos et al., (2011) diversos trabalhos sobre climatologia destacam a importância das análises em nível regional e local cujos efeitos na variabilidade climática continuam pouco explorados.

Com base neste contexto o presente trabalho tem como objetivo avaliar a variabilidade climática espaço-temporal da microrregião do Brejo Paraibano.

\section{MATERIAL E MÉTODOS:}


A área de estudo é a microrregião do Brejo Paraibano composta por 8 municípios, sendo eles: Alagoa Grande, Alagoa Nova, Areia, Bananeiras, Borborema, Matinhas, Pilões e Serraria (Figura 1), localizada na mesorregião do Agreste Paraibano. Segundo o IBGE 2010 (Instituto Brasileiro de Geografia e Estatística) a microrregião do Brejo Paraibano possui uma população de 116.488 habitantes e uma área total de $1.174,168 \mathrm{Km}^{2}$.
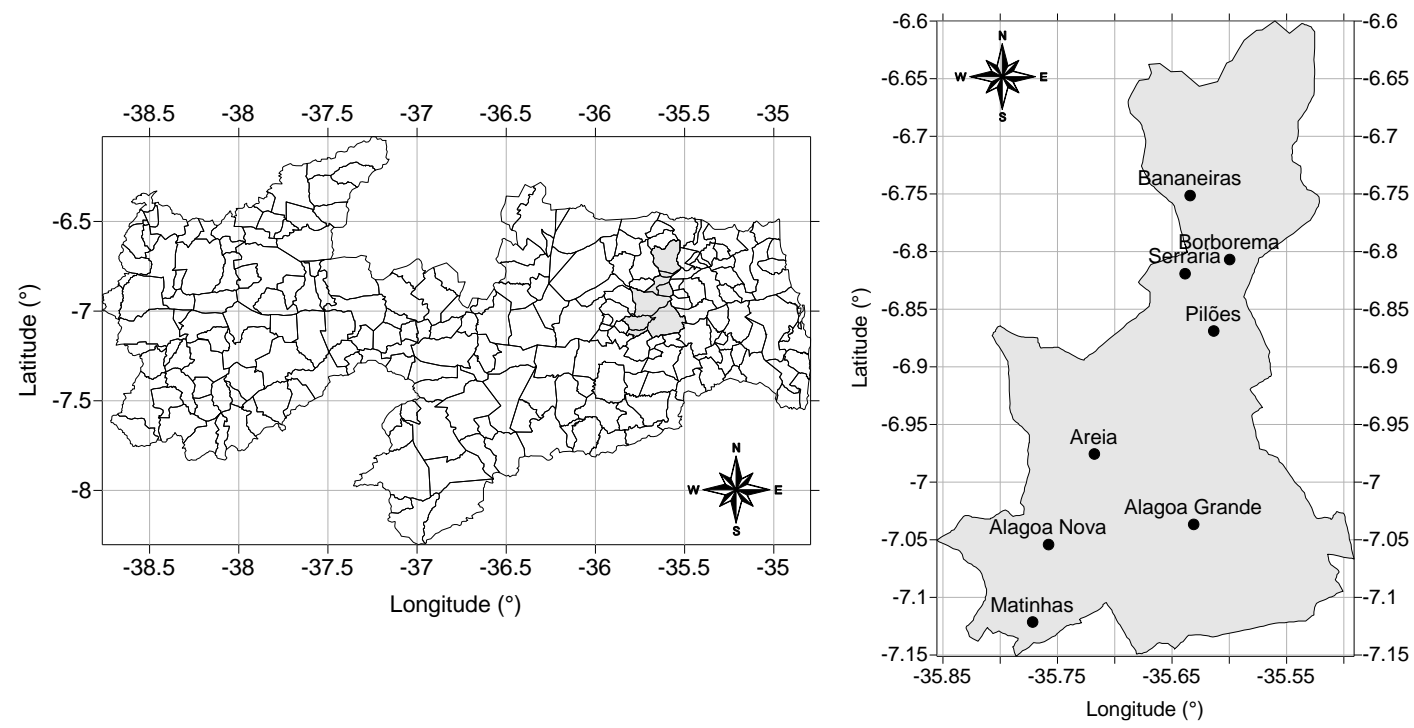

Figura 1 - Localização da Microrregião do Brejo Paraibano.

Os dados pluviométricos mensais foram fornecidos pela AESA (Agência Executiva de Gestão das Águas do Estado da Paraíba) para o cálculo do Índice de Anomalia de Chuva (IAC) adaptado por (FREITAS, 2005) e readaptado por (ARAÚJO et al., 2009).

As equações 1 e 2 dispostas a seguir são para a aplicação do IAC:

- para anomalias positivas

$$
\begin{aligned}
\text { IAC } & =3\left[\frac{(\mathrm{N}-\overline{\mathrm{N}})}{(\overline{\bar{M}}-\overline{\mathrm{N}})}\right] \\
& - \text { para anomalias negativas } \\
\text { IAC } & =-3\left[\frac{(\mathrm{N}-\overline{\mathrm{N}})}{(\overline{\mathrm{X}}-\overline{\mathrm{N}})}\right]
\end{aligned}
$$

\section{Sendo:}

$\mathrm{N}$ - precipitação mensal atual, $\mathrm{mm}$

$\overline{\mathrm{N}}$ - precipitação média mensal da série histórica, $\mathrm{mm}$

$\overline{\mathrm{M}}$ - média das dez maiores precipitações mensais da série histórica, $\mathrm{mm}$

$\overline{\mathrm{X}}$ - média das dez menores precipitações mensais da série histórica, $\mathrm{mm}$ 
Sob o ponto de vista climatológico, séries como estas são consideradas bastantes curtas, entretanto, de acordo com Santos et al. (2011) isso permite formular hipóteses sobre tendências de aumento ou redução das chuvas em condições atmosféricas extremas. Conforme tais autores, para a aplicação do IAC é recomendável a utilização de séries históricas com pelo menos 30 anos de dados. Sendo assim, caso a série possua menos de 30 anos faz-se necessária uma adaptação na quantidade de médias a serem utilizadas no cálculo do IAC, de forma que seja proporcional a quantidade de dados. Neste caso, em uma série de 21 anos, deve-se calcular as sete maiores e sete menores precipitações totais do período analisado.

Após analisar os dados da microrregião do brejo Paraibano classificamos os anos secos e chuvosos de acordo com a Tabela 1 adaptada por (ARAÚJO et al., 2009).

Tabela 1 - Classe de intensidade do índice de anomalia de chuva.

\begin{tabular}{ccc}
\hline & Faixa do IAC & Classe de Intensidade \\
\cline { 2 - 3 } & De 4 acima & Extremamente Úmido \\
Índice de Anomalia & 2 a 4 & Muito Úmido \\
de Chuva (IAC) & 0 a 2 & Úmido \\
& 0 a -2 & Seco \\
& -2 a -4 & Muito Seco \\
& De -4 abaixo & Extremamente Seco \\
\hline
\end{tabular}

\section{RESULTADOS E DISCUSSÃO}

A espacialização temporal da Microrregião do Brejo Paraibano mostra que a precipitação média mensal da região é de $95,9 \mathrm{~mm}$ e apresenta dois períodos distintos, um úmido e um seco. O período chuvoso ocorre entre os meses de fevereiro a agosto, sendo o mês de junho o mais expressivo atingindo uma precipitação média de $184,9 \mathrm{~mm}$ e o período seco ocorre entre os meses de setembro a janeiro, sendo outubro o mês mais seco com precipitação média de 18,2 mm (Figura 2).

Vale ressaltar, que o período chuvoso que ocorre entre os meses de fevereiro a agosto tem grande importância para inúmeras atividades produtivas, tais como a agricultura, pecuária e o aporte hídrico da região, sendo também a época com maior quantidade de recurso hídrico para fauna e flora. Essas atividades têm uma grande influência na economia da microrregião, devido a produção de laranja, banana e a cana de açúcar para os engenhos produtores de cachaça, dentre outros. 


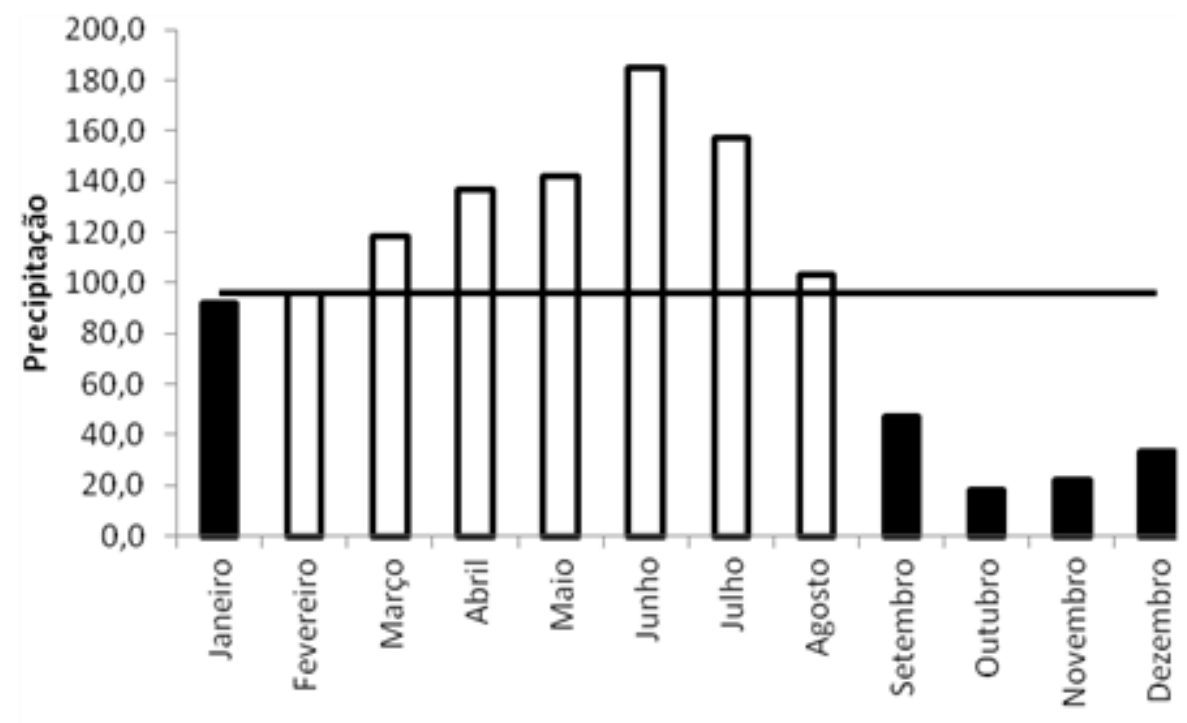

Meses

Figura 2 - Variabilidade temporal da Microrregião do Brejo Paraibano.

Para um melhor entendimento sobre o comportamento da precipitação os dados da série histórica foram espacializados mostrando a distribuição da precipitação na microrregião do Brejo Paraibano.

A)

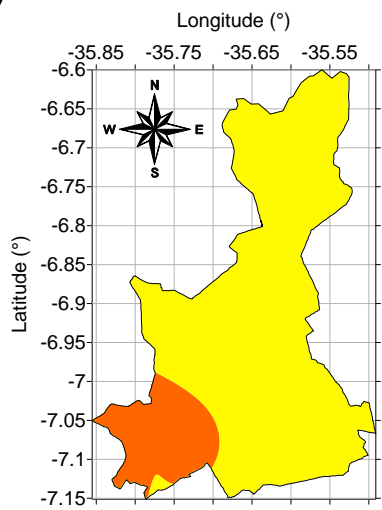

D)

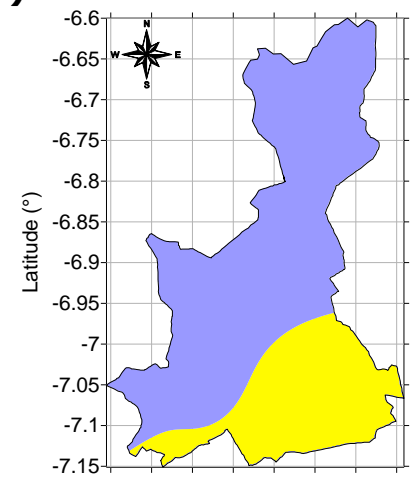

G)
B)

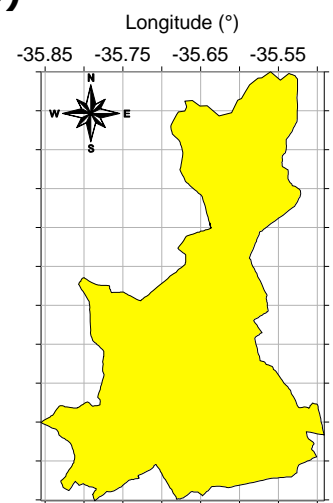

E)

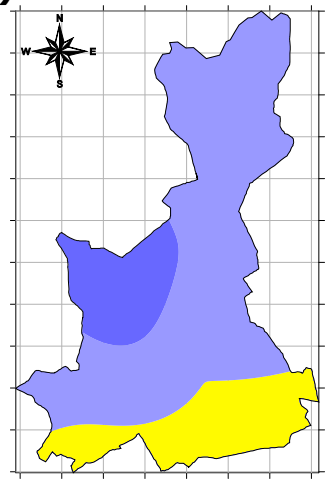

H)
C)

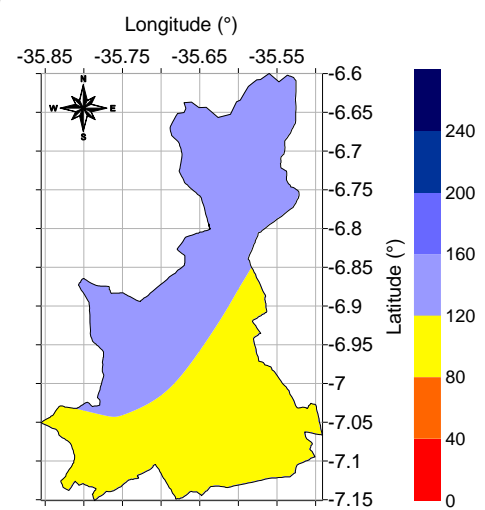

F)

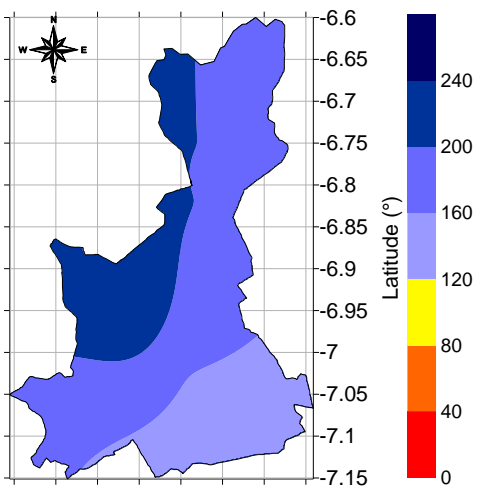

I) 


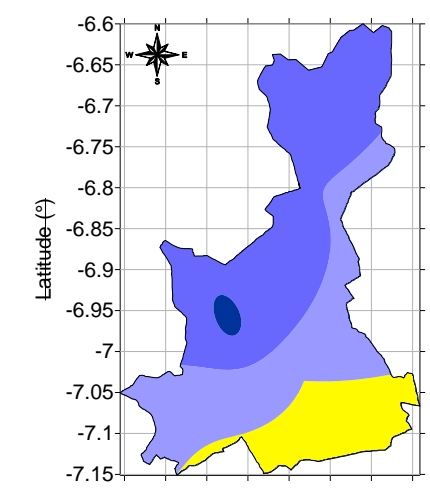

J)

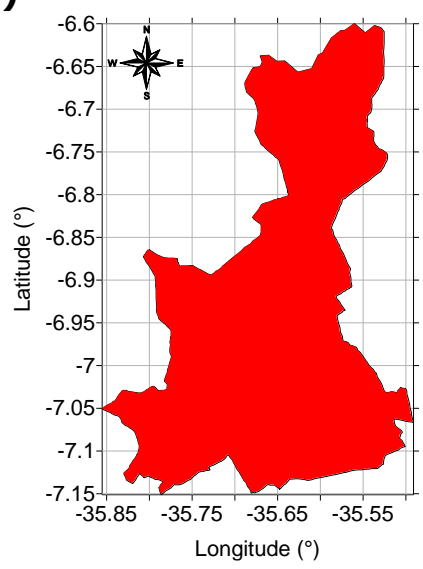

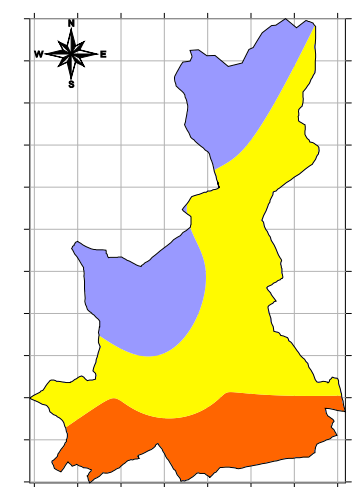

K)

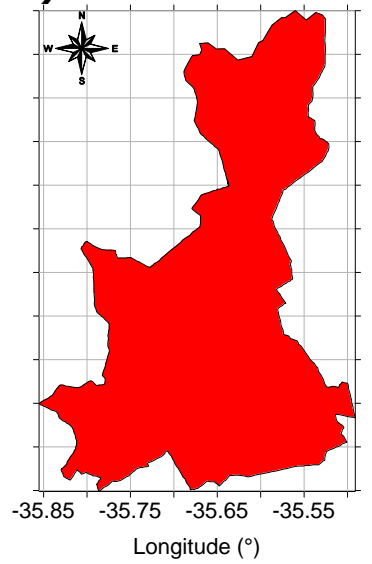

L)
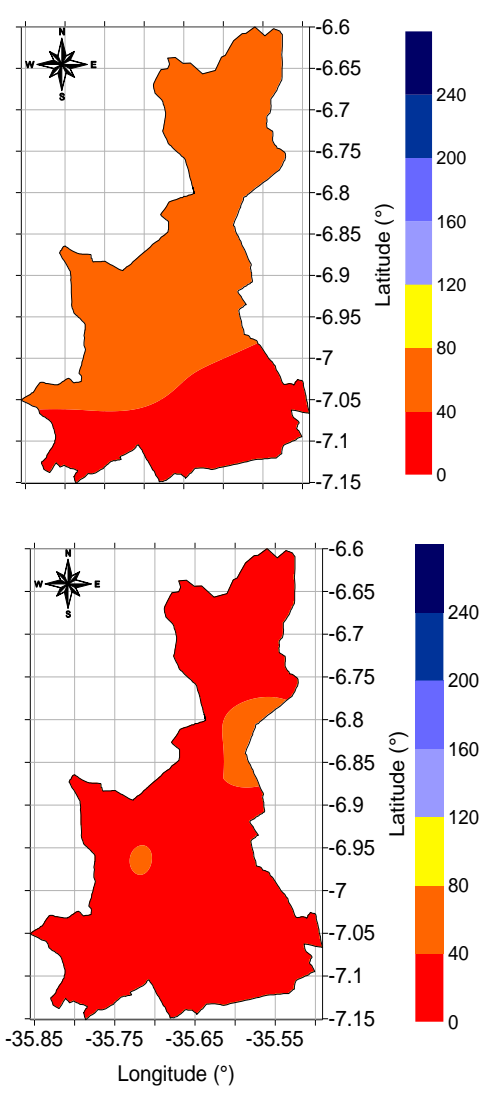

Figura 3 - Variabilidade espacial da microrregião do Brejo Paraibano dos meses de A) Janeiro, B) Fevereiro, C) Março, D) Abril, E) Maio, F) Junho, G) Julho, H) Agosto, I) Setembro, J) Outubro, K) Novembro e L) Dezembro.

Observa-se na (Figura 3) a distribuição espacial da precipitação na microrregião do Brejo Paraibano. A (Figura 3 I, J, K, L e A) correspondem aos meses de setembro a janeiro, os quais caracterizaram o período seco, de acordo com a (Figura 2), no qual a precipitação máxima não ultrapassa os 120 $\mathrm{mm}$ com distribuição espacial homogênea, sendo os meses de outubro e novembro os mais secos (Figura $3 \mathrm{~J}$ e $\mathrm{K}$ ).

A (Figura 3 B, C, D, E, F, G e H) correspondem aos meses de fevereiro a agosto, os quais são caracterizados como período úmido, ou seja, a estação chuvosa, visto que a precipitação mínima é de $80 \mathrm{~mm}$ e a máxima atinge os $240 \mathrm{~mm}$, com grande variabilidade espacial da precipitação. O mês mais representativo é o mês de junho, com precipitação mínima de $160 \mathrm{~mm}$ e máxima de $240 \mathrm{~mm}$, com uma maior variabilidade de precipitação na região Oeste/Noroeste da microrregião.

Para melhor avaliar a variabilidade do clima da microrregião do Brejo Paraibano aplicou-se o Índice de Anomalia de Chuva (IAC), cujo resultado demonstra-se em ciclos de anos chuvosos intercalados com ciclos de anos secos. Ressalta-se uma predominância de treze anos secos, classificados como seco (1995, 1997, 2002, 2003, 2005, 2013 e 2014), muito seco (1999, 2001, 2006, 2010 e 2012) e extremamente seco (1998) e apenas oito anos foram úmidos, classificados como úmido (1996, 2007 e 2008), muito úmido (2009 e 
2011) e extremamente úmido (1994, 2000 e 2004) (Figura 4) de acordo com a classificação da Tabela 1.

Mesmo com uma série histórica relativamente curta, pode-se observar como é o padrão do comportamento climático da microrregião, no qual um ano úmido é intercalado por um ano seco, com pequenas variações ao longo da série, mostra-se assim um comportamento adequado para a fauna, flora e as demais atividades humanas.

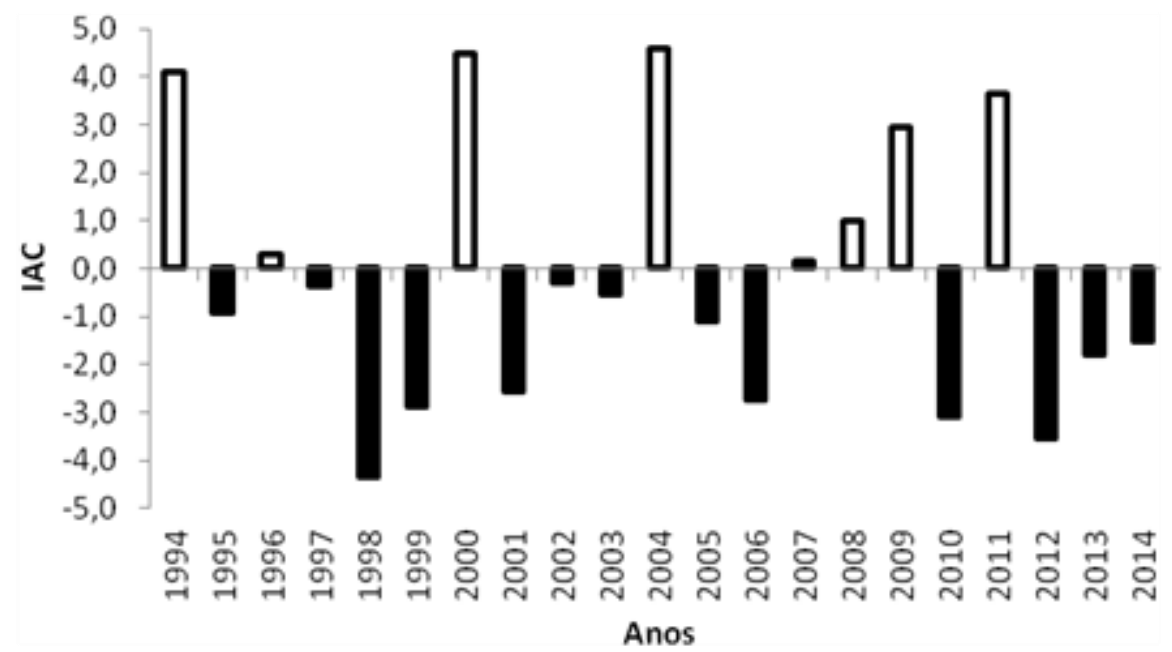

Figura 4 - Índice de Anomalia de Chuva (IAC) da Microrregião do Brejo Paraibano.

Para uma melhor avaliação das anomalias e severidade dos anos secos, separou-se os dois anos mais secos da série histórica. Neste caso a (Figura 5) mostra o IAC da microrregião do Brejo Paraibano dos anos secos de 1998 e 2012, ou seja, os anos que apresentaram IAC negativos. Observou-se que dentro do período seco que vai de setembro a janeiro (Figura 2), janeiro de 2012 apresenta-se positivo, contudo dentro do período chuvoso quatro meses têm IAC negativos, sendo eles fevereiro e abril de 1998 e março, abril e agosto de 2012. Corroborando com Freire et al., (2011) que afirma que o ano de 1998 apresentou os valores da temperatura do trimestre FMA (fevereiro, março e abril) mais elevado em toda a região Nordeste, ao fato de ter ocorrido um evento de El Niño neste ano, sendo assim o ano de 1998 classificou-se como extremamente seco, devido a este fenômeno ser um dos principais fenômenos responsáveis pela seca no Nordeste Brasileiro, para esse ano em específico. 


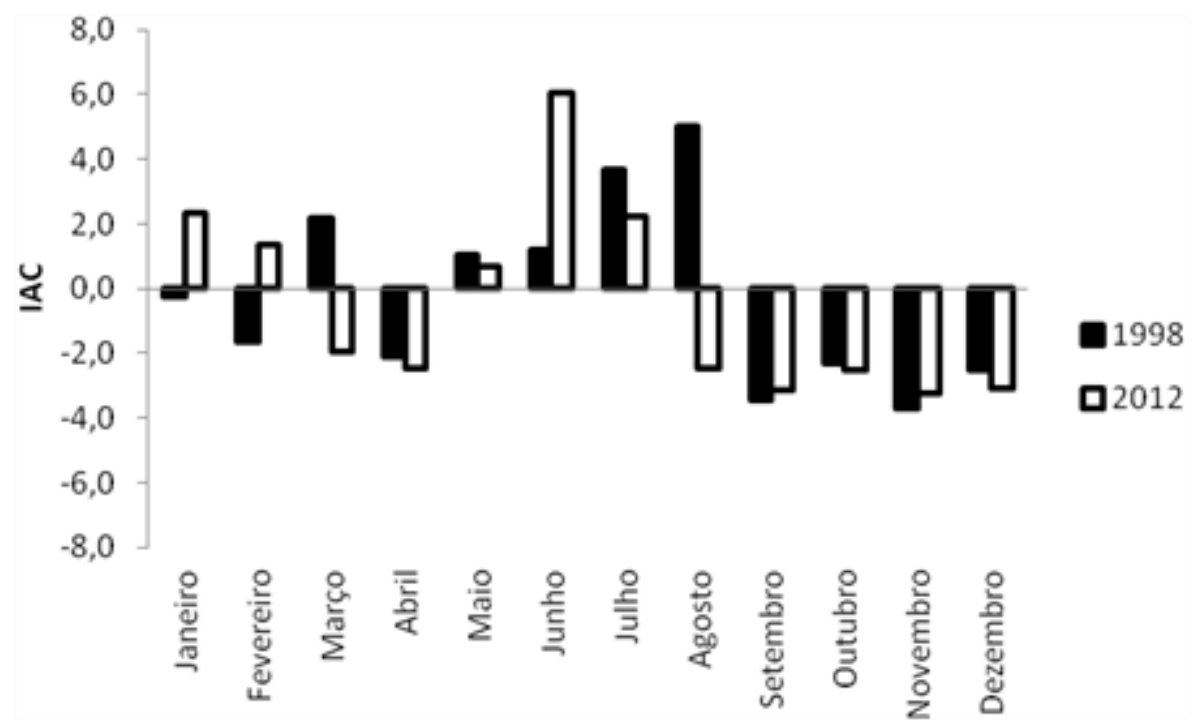

Figura 5 - Índice de Anomalia de Chuva (IAC) mensal para os anos secos da Microrregião do Brejo Paraibano.

De forma similar aos anos secos, avaliou-se a severidade da precipitação dos anos úmidos, separou-se os dois anos mais úmidos da série histórica. Sendo assim, a (Figura 6) apresenta o IAC da microrregião do Brejo Paraibano dos anos úmidos de 2000 e 2004, ou seja, os anos que apresentaram IAC positivo. Observa-se que dentro do período chuvoso o IAC apresenta-se negativo nos meses de fevereiro, março e maio de 2000 e março, abril, maio, junho, julho e agosto de 2004. Contudo, dentro do período seco que vai de setembro a janeiro, dois meses apresentaram IAC positivo, foram eles setembro de 2000 e janeiro de 2004. Evidenciou-se também que dentro do período chuvoso da microrregião, no ano de 2004 apenas fevereiro apresentou IAC positivo. De acordo com Brito \& Braga (2004) as fortes chuvas ocorridas na Paraíba em janeiro e fevereiro de 2004 foram as mais intensas dos últimos 50 anos e foram produzidas pela interação da ZCIT com as atividades convectivas oriundas do vórtice ciclônico da alta troposfera; conforme esses autores a posição do Vórtice Ciclônico foi fundamental na produção de chuvas na Paraíba em janeiro e fevereiro. 


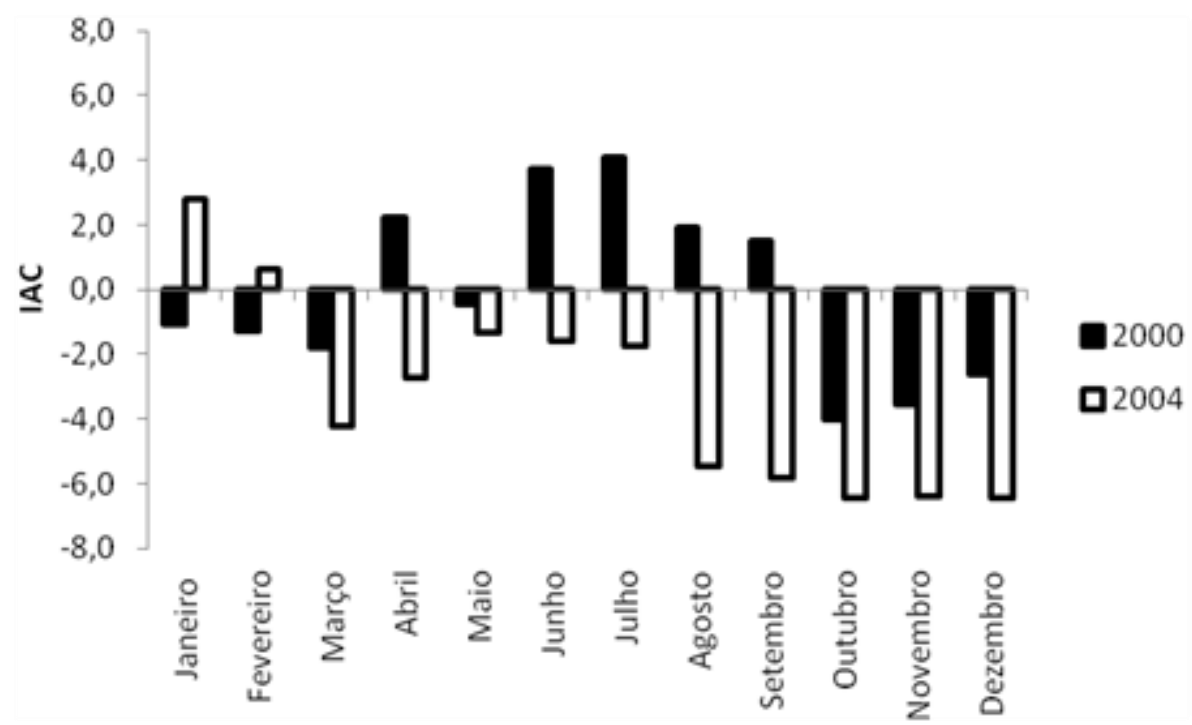

Figura 6 - Índice de Anomalia de Chuva (IAC) mensal para os anos úmidos da Microrregião do Brejo Paraibano.

\section{CONCLUSÕES}

O período úmido da microrregião do Brejo Paraibano vai de fevereiro a agosto, com o mês de junho sendo o mais representativo em precipitação e o período seco se dá de setembro a janeiro, sendo o mês de outubro o mais seco com menor quantidade de precipitação.

A climatologia espacial identifica uma melhor distribuição da chuva na microrregião do Brejo Paraibano na região Oeste/Noroeste da microrregião.

O Índice de Anomalia de Chuva mostra uma predominância de anos secos, com treze anos secos e apenas oito anos úmidos, no entanto intercalados entre si, resultado este de extrema importância na oscilação entre os períodos secos e chuvosos da região. Os anos secos se apresentam mais coesivos com as características de cada período (seco e úmido), onde 1998 e 2012 apresentaram apenas seis meses em desacordo com as características de cada período, comparados com os anos úmidos (2000 e 2004) que apresentaram onze meses em desconformidade com as características dos seus respectivos períodos.

Desta forma, a partir dos resultados observados pose-se afirmar que a melhor época para o plantio e aporte hídrico na microrregião do Brejo Paraibano é entre os meses de fevereiro a agosto, ao fato de ser o período chuvoso. O qual tem grande importância para economia da microrregião, pois, boa parte desta depende de atividades agrícolas como o cultivo da cana de açúcar, produção de laranja e banana, entre outras culturas cultivadas na região. 


\section{REFERÊNCIAS}

ARAÚJO L. E., SOUSA F. A. S., RIBEIRO M. A. F. M., SANTOS A. S. \& MEDEIROS P. C. Análise estatística de chuvas intensas na bacia hidrográfica do rio Paraíba. Revista Brasileira de Meteorologia, v.23, n.2, 162-169, 2008.

ARAÚJO L. E., NETO J. M. M. \& SOUSA F. A. S. Análise climática da bacia do rio Paraíba - Índice de Anomalia de Chuva (IAC). Engenharia Ambiental - Espírito Santo do Pinhal, v. 6, n. 3, p. 508-523, 2009.

ARAÚJO L. E., NETO J. M. M. \& SOUSA F. A. S. Classificação da precipitação anual e da quadra chuvosa da bacia do rio Paraíba utilizando o Índice de Anomalia de Chuva (IAC). Ambi-Agua, Taubaté, v. 4, n. 3, p. 93-110, 2009.

BRITO, J. I. B., BRAGA C. C. Chuvas no estado da Paraíba em 2004. Boletim SBMET, p.27-32, 2005.

ESPINOZA, E. S. Distúrbios nos ventos de leste no Atlântico Tropical. São José dos Campos: INPE, 1996. 127p. Dissertação Mestrado

FREIRE J. L. M., LIMA J. R. A., CAVALCANTI E. P. Análise de Aspectos Meteorológicos sobre o Nordeste do Brasil em Anos de El Niño e La Niña. Revista Brasileira de Geografia Física, p. 429-444, 2011.

FREITAS A. C. V., FRANCHITO S. H. \& RAO V. B. Análise dos dados de precipitação provenientes de diferentes fontes, sobre a América do Sul, com ênfase no Brasil. CLIMEP - Climatologia e Estudos da Paisagem Rio Claro (SP) - Vol.5 - n.1 2010.

KOUSKY, V. E. Frontal influences on northeast Brazil. Monthly Weather Review, v.107, p.1140-1153, 1979.

KOUSKY, V. E.; Gan, M. A. Upper tropospheric cyclones vortices in the tropical south atlantic. Tellus, v.33, p.538-551, 1981.

PEREIRA S. S. \& CURI R. C. Condições climáticas e recursos hídricos: análise da atual situação hídrica do estado da Paraíba, Brasil. I Workshop Internacional Sobre Água no Semiárido Brasileiro Campina Grande - PB 2012.

SANTOS E. C. A., ARAÚJO L. E. \& MARCELINO A. S. Análise climática da bacia hidrográfica do rio Mamanguape. Revista Brasileira de Engenharia Agrícola e Ambiental, v.19, n.1, p.9-14, 2015.

SANTOS E. P., CORREIA M. F., ARAGÃO M. R. S. \& SILVA F. D. S. Eventos extremos de chuva e alterações no regime hidrológico da bacia hidrográfica do rio São Francisco: uma aplicação do índice RAI (Rainfall Anomaly Index). Engenharia Ambiental - Espírito Santo do Pinhal, v. 8, n. 2, p. 315-330, 2011.

SILVA R. W. C. \& PAULA B. L. Causa do aquecimento global: antropogênica versus natural. TERRÆ DIDATICA 5(1):42-49, 2009.

SILVA V. P. R., CAVALCANTI E. P., NASCIMENTO M. G. \& CAMPOS J. H. B. C. Análises da precipitação pluvial no Estado da Paraíba com base na teoria da entropia. Revista Brasileira de Engenharia Agrícola e Ambiental, v.7, n.2, p.269-274, 2003. Campina Grande, PB, DEAg/UFCG http://www.agriambi.com.br. 
UVO, C. R. B. A zona de convergência intertropical (ZCIT) e sua relação com a precipitação na região Norte e Nordeste brasileiro. São José dos Campos: USP. 1989. 99p. Dissertação Mestrado 